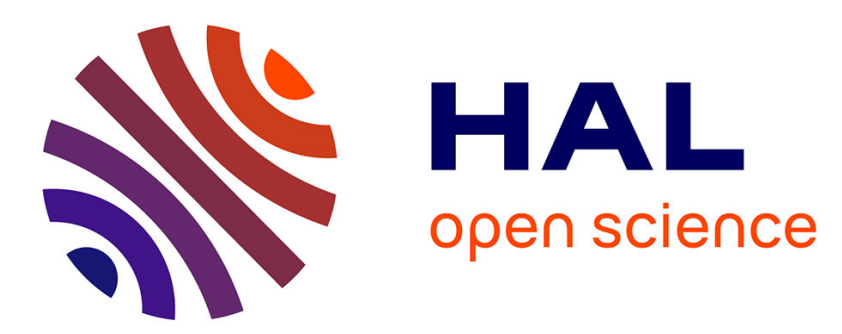

\title{
RTI Images for Documentation in Archeology: The Case of the Iron Age Female Terracotta Figurines from Busayra, Jordan
}

Regine Hunziker-Rodewald, Peter Fornaro

\section{- To cite this version:}

Regine Hunziker-Rodewald, Peter Fornaro. RTI Images for Documentation in Archeology: The Case of the Iron Age Female Terracotta Figurines from Busayra, Jordan. Journal of Eastern Mediterranean Archaeology \& Heritage Studies, 2019, 7 (2), pp.188-204. 10.5325/jeasmedarcherstu.7.2.0188 . hal03083281

\section{HAL Id: hal-03083281 \\ https://hal.science/hal-03083281}

Submitted on 18 Dec 2020

HAL is a multi-disciplinary open access archive for the deposit and dissemination of scientific research documents, whether they are published or not. The documents may come from teaching and research institutions in France or abroad, or from public or private research centers.
L'archive ouverte pluridisciplinaire HAL, est destinée au dépôt et à la diffusion de documents scientifiques de niveau recherche, publiés ou non, émanant des établissements d'enseignement et de recherche français ou étrangers, des laboratoires publics ou privés. 


\title{
RTI Images for Documentation in Archeology
}

\section{The case of the Iron Age female terracotta figurines from Busayra, Jordan*}

\author{
Regine Hunziker-Rodewald (Strasbourg, France) and Peter Fornaro (Basel, Switzerland)
}

Les numéros correspondant à la pagination de la version imprimée sont placés entre crochets dans le texte et composés en gras.

\section{<190> I Buṣayra in southern Jordan (R. Hunziker-Rodewald)}

During the years 1971-1974 and 1980, Crystal-M. Bennett conducted excavations at a fortified hill settlement south of Wadi al-Hasa in southern Transjordan, situated between Wadi Arabah and the Syrian Desert, 4 km west of the so-called King's Highway (Bienkowski 2002: 37-38). Bennett was not the first one to identify that site north of the present-day town of Al-Bușeirah with biblical Boșrah, in Hebrew "the inaccessible one". ${ }^{1}$ In the Isaiah

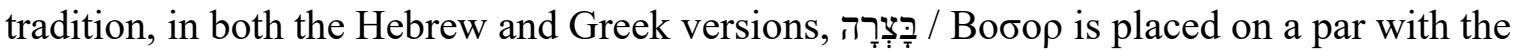
land of Edom ${ }^{2}$ which might underline the regional importance of the site. Whether Boșrah was, at least temporarily, Edom's capital, however, cannot be decided yet. ${ }^{3}$ Apart from that question, one of the main reasons for Bennett's choice of site for her excavations was its proximity to the Wadi Faynan mining district (Bienkowski 1990: 101) ${ }^{4}$ which, at this geographical point only, is connected to the Edomite Highlands by a break in the cliffs. ${ }^{5}$

\footnotetext{
${ }^{*}$ Régine Hunziker-Rodewald et Peter Fornaro, « RTI Images for Documentation in Archeology: The Case of the Iron Age Female Terracotta Figurines from Bușayra, Jordan », Journal of Eastern Mediterranean Archaeology and Heritage Studies 7/2 (2019), p. 188-204.

${ }^{1}$ From Hebrew $b s+r$ "cut off, separate". The site is surrounded by steep ravines and connected to the high plateau only in the south-east.

${ }^{2}$ Isa. 34:6, 63:1, cf. also Gen. 36:33 // 1Chr. 1:44. On Edom see Weippert 1982; Bartlett 1989.

${ }^{3}$ Additional settlement structures within the perimeter wall were identified in 2014-2015 by a team from Berkeley University during a geophysical survey (Brown et al. 2016).

${ }^{4}$ Radiocarbon dates demonstrate continuous smelting activities in Wadi Faynan since the tenth century BCE (Levy et al. 2008: 16465).

${ }^{5}$ On the relationship between the mining district (500 sq. km, about 250 mining sites, Kafafi 2014: 263) and the Edomite plateau, see Finkelstein and Singer-Avitz 2009.
} 


\section{$<191>$ I.1 The site and its female figurines}

Henceforth we will refer to the site by its conventional designation of "Buṣayra". In its ruins, 19 female terracotta figurines were discovered. Eighteen of them were found in the lower town (Area B) situated between the south-western perimeter wall and the stone platform supporting the large open-court structure in Area A (Bienkowski 2002: 137). ${ }^{6}$ The architectural remains in Area A probably belong to a public installation consisting of two large buildings constructed on top of each other in such a way that the later building from the sixth or fifth century BCE replaced the earlier, larger building from the late eighth or seventh century BCE (Reich 2011: 305). In the adjacent Area B, where the 18 female figurines were found, small rectangular structures built against the perimeter wall suggest a domestic occupation probably by the personnel - servants and/or priests - of the large buildings in Area A and C, in its south-west, where a residence or palace was identified (Bienkowski 2002: 199.476).

\section{I.2 Stratigraphy and dating}

Bușayra is only excavated to a small extent, therefore the stratigraphic connections between the areas $\mathrm{A}-\mathrm{D}, \mathrm{H}$, and $\mathrm{M}$ are uncertain; nevertheless, the editor of the final excavation report has established an absolute phasing of the excavated zone. An absolute dating relative to two identified destruction episodes has been suggested for the integrated stages throughout the site. According to these propositions, one half of the female figurines in Area B have to be assigned to a settlement phase which preceded the mid-sixth century BCE, ${ }^{7}$ while the other

\footnotetext{
${ }^{6}$ One figurine head (Reg. no. 457, Sedman 2002: 370) was found about $100 \mathrm{~m}$ east of the other eighteen figurines, within the north-eastern walls of the earlier building B in Area A (A1.10), in the topsoil layer (Bienkowski 2002: 58-59.96).

${ }^{7}$ Integrated stage 2 (seventh century to 553 BCE), Bienkowski 2002: 476.
} 
half $^{8}$ of the $<\mathbf{1 9 2}>$ figurines belong to a settlement phase which extends from the mid-sixth to, at the latest, the end of the third century BCE. ${ }^{9}$

Against this background, given the typological similarity of the figurines, ${ }^{10}$ questions arise about the long-term use of these objects or the possibility of heirlooms, and about the longevity of molds or mold generations (e.g. molds taken from molded figurines in case the original mold is worn or broken). The typology of the figurines might even relativize the postulated absolute stratigraphy and its dating. In any case, detailed comparisons of typology, of potential mold-links (e.g. figurines made from the same mold) and the identification, as appropriate, of mold generations (Hunziker-Rodewald 2017: 67.76.91-93) will be useful and reliable only if we use high-precision, reproducible and true-color photographic recordings, digitally sensed models of the surface and virtually reconstructed complete shapes of these image media. ${ }^{11}$

\section{I.3 Issues of context and interpretation}

The 18 female figurine fragments excavated in Bușayra were found in a base area of about 20 by $20 \mathrm{~m}, 11$ of them accumulated in only four different trenches. ${ }^{12}$ This (random) pattern is unusual and hardly corresponds to the distribution of figurines within residential contexts. ${ }^{13}$ In

\footnotetext{
${ }^{8}$ Except one of the figurines in B6 (Reg. 969) that was found in the topsoil layer (Sedman 2002: 371).

${ }^{9}$ Integrated stage 3 (553 to 300/200 BCE), Bienkowski 2002: 476.

${ }^{10}$ The female figurines' corpus of Area B consists of seven heads, three busts, six torsos and two pairs of legs. All these fragments were made in deep single molds so that the front and the sides are represented in high relief. Especially the legs, torsos and busts show that the back was flattened, so these figurines were neither made in the round nor were they freestanding. They should not be called "(low-relief) plaques" as in the vast majority of cases there is no excess of clay around the represented figurine. These high-relief figurines were not produced by pressing a mold on a clay plaque, but by filling clay into a deep mold, removing the protruding clay, finishing the figurine taken from the mold on three sides and flattening the back. In the Bușayra corpus, due to poor documentation, it is impossible to say if some heads and torsos or legs and torsos/busts can be joined.

${ }^{11}$ See below part II. Identified mold-links are a methodologically important "tool" for revealing the local and (trans-)regional network of tradition and innovation as well as the migration of people and ideas, cf. HunzikerRodewald 2017. Drawings alone - which often are simplified and always represent a subjective approach to shape and iconography - can by no means be sufficient to draw far-reaching conclusions regarding cultural dependency and exchange (see e.g. Bienkowski and Sedman 2001: 312; Sedman 2002: 374-375).

${ }^{12}$ Trenches B1.2 and B6.3: two figurines each; trench B3.2: three figurines; trench B2.7: four figurines (Sedman 2002: 369-374).

${ }^{13}$ See Kletter 1996: 107-113 (maps showing the location of JPFs in seven occupation structures in Cisjordan).
} 
Trench B2.7, three of the four female figurines have been found even in the same locus (B2.7.4) which, besides ashes and clay, contained fragments of burnt painted pottery. The huge amount of very fine pottery, to a fair extent without signs of usage (Bennett 1973: 11), and of luxury goods such as a part of a rim of an inscribed Egyptian chalice and an engraved Tridacna squamosa shell in Area B, whereas the temple ${ }^{14}$ buildings in Area A produced significantly less finds, is striking.

This fact led the excavator to the idea that the buildings in Area A were sacked and the pottery (and the figurines) thrown against the city wall in Area B (Bennett 1973: 11; 1974: 1). ${ }^{15}$ Should this assumption be acceptable, then we can ask: were these figurines - some of which were painted and at least seven of them represent pregnant women about to give birth ${ }^{16}$ - ex-votos dedicated to the temple after a safe birth? ${ }^{17}$ The thesis becomes all the more probable as four more fragments (legs, torso, bust) could also represent pregnant women apart from the seven remaining heads which to date cannot be classified as belonging to a pregnant body. In order to be able to assign these fragments, a documentation of the highest photographic level using software that allows for multiple edits of the captured data is required, with which fragments can be virtually measured, compared and recreated (see below part II).

Apart from the fragmentary state of conservation and the unsecured archaeological context of the Bușayra figurines, a further problem, which is due to find-sharing procedures between the sponsors of the Bennett excavation, is the distribution of these artifacts between eight museums located on three continents. Therefore, they can probably never again be checked

\footnotetext{
${ }^{14}$ For the possible interpretation of Area A as a temple area cf. Bienkowski 2002: 94-95.

${ }^{15}$ But see the critique of this idea in Bienkowski 2002: 126.

${ }^{16}$ The swollen vulva of Reg. 637, see below, is not "exaggerated" or "grotesque" (Sedman 2002: 370). On the position of the vulva on the Iron Age female figurines from Transjordan see Hunziker-Rodewald 2019a.

${ }^{17}$ One of the figurine heads has been found in the building in Area A (see above footnote 7). Concerning the interpretation of the Iron Age female figurines from Jordan as representing the reproduction phases of women see Hunziker 2017; 2018; 2019a; 2019b. The paint was probably applied after firing, that is why it often faded away.
} 
and compared side by side. Whether some isolated heads match the bodies can be decided only by using the same technology for recording these fragments for the purpose of virtual comparability, which is the main approach when dealing with typology.

\section{I.4 Issues of typology - the problem}

The Bușayra female figurines differ typologically from every other figurines' corpus in Transjordan for at least two reasons (this, however, can only be asserted for each fragment if conditions allow for a classification): 1 . they represent a heavily pregnant woman 2 . whose hair is covered partly or completely by a hood or a veil which in most cases hides the ears (Sedman 2002: 369-374). ${ }^{18}$ While the portrayal of a terracotta female exhibiting advanced pregnancy is rare if not unique in the Southern Levant, ${ }^{19}$ several veiled or hooded female terracotta heads are known from Horvat Qitmit in the Negev desert. ${ }^{20}$ In that respect, the female figurines from Bușayra could refer to contacts along the trade route connecting Arabia with Gaza via Bușayra, Horvat Qitmit and Beersheba. ${ }^{21}$ The typology of the female figurines east and west of the Arabah, especially their hooded or veiled heads, with local peculiarities, ${ }^{22}$ testify in the field of material culture to a local, Edomite, tradition $<\mathbf{1 9 3}>$ in the area, which might indicate that the actual trade was less Assyrian-controlled ${ }^{23}$ and was more likely to be carried out by Arabian tribes themselves (Bienkowski, oral communication).

\footnotetext{
${ }^{18}$ Reg. 656 shows ears, contra Sedman 2002: 368 (the photo pl. 10.40 on p. 370 is blurred).

${ }^{19}$ See Bienkowski 1995: 80.292 fig. 9.3:1 (from Tawaylan) and Beck 1995: 100-101 fig. 107 (from Horvat Qitmit), these figurines probably show (early) pregnancy, cf. the call for caution by Sedman 2002: 375. See especially the Late Bronze Age molded glass pendants from several Levantine sites exhibiting advanced pregnancy (Tufnell 1958: 2 pl. 27:2; Barag 1985: 145 and pl. 2:15-16; Spaer 1991: 152 Fig. 65, 153 no. 281, $356 \mathrm{pl} .23: 281$ ). As they are once or twice pierced (at shoulder/knee level) they seemingly served as amulets (worn e.g. on a necklace), an issue that must be considered when interpreting "pregnant figurines", see Hunziker-Rodewald 2018; 2019b.

${ }^{20}$ Beck 1995: 107 (Horvat Qitmit); see also Kletter 2014: 548 fig. 9.2:5 (Tel Malhata).

${ }^{21}$ See the identification of Edomite pottery in the eighth-century BCE "way station" of Beersheba by SingerAvitz 2004.1999: 30-39.

${ }^{22}$ Five figurines of the Bușayra corpus (Reg. 98.190.298.457.747, maybe also 285.637.656) show on the forehead the rim of an additional headband (or is it a two-piece veil?).

${ }^{23}$ Contra Finkelstein and Singer-Avitz 2009.
} 
In order to be able to grasp exactly the peculiarity of the presumed Edomite local culture along a possible connection between Bușayra, 'En Haẓeva, Tel Malhata, Tel 'Ira and Beersheba based on female figurines' typology, the researchers should have better data to hand than blurred photos and simplified drawings which, by being compared, further multiply the uncertainties. ${ }^{24}$

To sum up, we state: 1 . drawings are subjective interpretations; comparative studies based on drawings alone are methodologically untenable; 2. the postulation of mold-links based on personal conviction that cannot be verified by the reader through corresponding detailed photographical recordings (including digital measurements) is useless; 3 . worn fragments that are not digitally documented with utmost care are lost to research; 4. fragments of the same type of objects kept in (storage facilities of) remote collections and attested in literature only by low-resolution photos and line drawings of minor quality are practically worthless for scientific evaluation within the scope of disciplines such as comparative art and cultural history; 5. in the case of the improper documentation of small-sized fragmentary artifacts made of unremarkable material, valuable information for example about non-elite practices in ancient societies is at risk of getting lost.

However, there are means against "groping in the dark" when interpreting such artifacts.

\section{Images for documentation (P. Fornaro)}

Images have a long tradition in documentation (Talbot 1844). They have always played a vital part in archeological research, especially for the purposes of documentation while doing excavations. Such reproductions allow researchers to take artifacts virtually back to their offices, where theories can be developed and discussed with their fellow colleagues. They are also important for the documentation of the current state of an artifact, e. g. one that is in the

\footnotetext{
${ }^{24}$ Kletter 2014: 569-570.572-573, cf. Bienkowski and Sedman 2001: 312; Sedman 2002: 374-375.
} 
process of restoration. Such documentation is particularly useful if the object is only accessible for a limited time, be it on site or while visiting a foreign museum.

A common solution is to work with photographs. They document the visual impressions of objects and can be a precise tool for capturing the state of an original, including its color, geometry and materiality. In addition, in the digital domain, new attributes can be advantageous: digital images can be easily shared, disseminated and given access to. Due to all of these advantages, digital images are an important part not only of art historical research, but of our cultural heritage in general, and they are an essential component of our contemporary multimedia output in social, scientific and economic fields.

However, when it comes to special attributes of artifacts such as surface roughness or its relief, static and two-dimensional photographs are not able to reproduce the variety of visual impressions by any means. Therefore, new approaches, technologies and methods are needed to translate characteristic features of archeological artifacts into the digital domain. Our computational-photography approach promises a more comprehensive way to capture, communicate and disseminate digital images of archeological pieces that goes far beyond conventional photography. New possibilities in computer technology and digital imaging have been developed to virtually transfer most of the relevant object features into the digital domain. Furthermore, these technological advances have brought a new standard in photographic quality. Color can be captured and rendered in much better quality, geometric distortion can be minimized and even interaction is provided in web-based environments.

\section{II.1 Technological approach: Reflectance Transformation Imaging}

A promising method to solve the above mentioned limitations is Reflectance Transformation Imaging (RTI). RTI is a set of computational photographic methods that capture a subject's surface shape and color and enables the later interactive re-lighting of the subject from any 
direction based on a mathematical surface model. To gain such RTIs, first the $<\mathbf{1 9 4}>$ reflection of light is captured by multiple photographs illuminated from different angles. Then, a mathematical term that describes the physics on the surface, typically a polynomial of second order, is fitted to the measured reflection for each pixel position. This approach is convenient from several points of view: only little hardware and software are needed to acquire such an image, and the stability and reproducibility of the mathematical fitting process are easy to guarantee thanks to a robust model.

The major drawback of this method is the lack of the ability to render any gloss of a surface. A second-order polynomial is able to reproduce the reflection of diffuse surfaces, also called a Lambertian surface, while the realistic reproduction of shininess is not possible. A Lambertian surface scatters the incoming light equally in each direction, in such a way that the apparent brightness does not depend on the observer's point of view. Although the radiance of the surface depends on the angle between the illuminating source and the orientation of a specific point on the surface, following the Lambertian cosine law, it does not depend on the point of view of the observer - it has a uniform reflection. A glossy surface, on the other hand, has a more or less strong component of specular reflection. Specularity means that light is reflected in one specific direction defined by the law of reflection (also called Snell's Law). A mirror is a perfect example of specular reflection. Another drawback is the RTI imaging workflow and the fact that the display of conventional RTIs needs a particular stand-alone application. The most advantageous way to work with RTI renderings is certainly a web environment based on standard technology, without plugins or other add-ons. There have been basic approaches to integrate an RTI viewer in web environments. Most of those implementations are still in the prototype phase or are not maintained well.

Therefore, we have improved RTI by the following means: 
- Using a data-driven approach to find a better model or actually a combination of multiple models to be able to reproduce Lambertian and glossy materials with as few parameters as possible.

- Using WebGL to render RTI images in any standard web browser, even on most mobile devices. Such a solution opens up various new applications and the possibility for collaborative work because the viewer can be embedded in a web environment.

Furthermore, scholars may want to integrate information coming from other types of scientific photographs, such as infrared or ultraviolet illuminated or induced fluorescence photography, to enrich the visual impressions of the artifact renderings with usually nonvisual aspects. The combination of such scientific photographs with RTI images is especially advantageous because multiple visual impressions can be combined in a way that would not be possible in reality (Fornaro et al. 2017).

\section{II.2 Hardware}

The developed mobile custom-made hardware consists of a dome structure made of a composition of aluminum and acrylic glass. The device is equipped with 48 high-luminance white-light LEDs powered by integrated electronics for automated capture with high reproducibility. The structure is approximately $50 \mathrm{~cm}$ in diameter and $35 \mathrm{~cm}$ in height. A standard high-resolution digital camera can be mounted on top of the structure. The full setup is calibrated before operation. Calibration includes the adjustment of intensity, white point of the LEDs and color correction of the capture. The LEDs can be synchronized with the camera by standard TTL flash-trigger signals. Besides LEDs in the visible range, UV or IR LEDs can also be controlled and therefore integrated in the measurement process to create an extended acquisition. 
The setup is mobile, battery-driven, highly flexible and especially designed for the purpose of RTI capturing on site (Fig. 1). The system can be configured to control the LED intensity by software. In addition, continuous light with all LEDs activated is possible for a very homogeneous illumination of the object in conventional digital photographs. The continuous full-light mode is optimal for various reproduction setups. The advantage of our approach is its compatibility with standard off-the-shelf camera equipment. It can be easily configured to automatically do sequential interval capture with any standard digital camera. The main advantages of this setup are its simplicity and robustness that lead to reproducible and calibrated results of high quality. Calibration is very important for RTI $<\mathbf{1 9 5}>$ image data because of the relevance of knowing exactly the position of the light source. By calibrating, larger collections of objects can be captured in a standardized, reproducible way without any additional error-prone human interaction. As a consequence, it allows for the study of light reflection on numerous types of surfaces and materials. Because of the identical capture of all images, results from various objects can be compared and conclusions can be drawn on the basis of precise and valid data. In addition, a well-documented and calibrated system is the key element for data sustainability. Only a reproducible, well-documented physical measurement process can lead to RTI image data files of sustainable scientific value.

\section{II.3 Software}

The strength of RTI is the possibility for the user to interactively change light direction. Therefore, a set of tools for rendering and interacting with RTI/PTM data in a web browser has been developed (Fig. 2). ${ }^{25}$ The viewer implements controls that allow the user to change the magnitude of the specular and diffuse part of the digital representation. The web-based approach opens up many new possibilities, for example the dissemination of digital

\footnotetext{
${ }^{25} \mathrm{http}: / /$ www.truvis.ch (accessed November 21, 2018).
} 
reproductions and the collaborative work between researchers. A specific binary executable stand-alone application limits any scientific discussion to a workstation. The software infrastructure required to support $<\mathbf{1 9 6}>$ such collaborative work goes beyond a standard web-server solution. Besides Regions of Interest (ROIs) and linked comments and annotations, the full set of viewing parameters must be stored as technical metadata within the system. Furthermore, any time-dependent changes of those viewing parameters must be tracked for reproducibility and traceability purposes as a reference for any future discussion. Such traceability is also necessary to be able to cite a specific situation a scholar may want to highlight.

\section{The figurine Bușayra Reg. 637 (R. Hunziker-Rodewald)}

The deep-molded bust Reg. 637 which is preserved from the head to the thighs is the most complete female figurine fragment of the Bușayra corpus. Already broken twice, at the neck and waist, in antiquity, it was mended after excavation and is now kept in the storage facilities of Karak Archaeological Museum in Jordan. With the generous permission of the Department of Antiquities in Amman, R. Hunziker-Rodewald and her team were able to take RTI images of this figurine in November 2012.

The fragment may serve as an example of the urgent need for the high-precision photographical recording of this kind of artifacts. It was presented the first time, with a line illustration (Fig. 3), in an unpublished doctoral thesis submitted to the University of Oxford in 1975 (Holland 1975: 2, 86, fig. 72:1). The explanations of the author Thomas A. Holland include: nude female plaque holding both breasts - single-molded without a clay "tablet" background - thick, squarish headdress which at present has no specific parallels elsewhere.

$<\mathbf{1 9 8}>$ In 1980, the figurine was again presented, with another line drawing (Fig. 4), in an unpublished $\mathrm{PhD}$ thesis submitted to the University of London ('Amr 1980: 350 fig. 24). The 
comments by the author Abdel-Jalil 'Amr include: figurine holding its breasts - traces of black paint on the back of the headdress, on the shoulders and thighs.

The drawing in 'Amr was reproduced in a publication from 1996 (Kletter 1996: 243 4.VIII.1). The comments of the author Raz Kletter on type 4.VIII.1 include: plaque figurine of a pregnant woman - type very different from the Late Bronze and early Iron Age plaque figurines - hands grasping the breasts, with the thumb separated from the other fingers faces quite crude, with sidelocks reaching the shoulders.

The comments of these specialists in Iron Age figurines from the ancient Levant show well their individual perception of details concerning the headdress/sidelocks, paint and finger position when describing the object. Due to the poor quality of the line drawings, no reader can verify and evaluate the information provided by these authors.

In 2002, the figurine Reg. 637 was reproduced again by a photo of a drawing with sharper contrast and outlines. ${ }^{26}$ The author Leonie Sedman had access to the piece in 1995 in Karak Archaeological Museum as well as to Bennett's excavation records in the National Museums Liverpool. Her comments include: traces of black paint in vertical stripes around the figure holding breasts - eyes shown by heavy incision - hair or headdress? - genital area exaggerated - obviously pregnant - necklace.

The drawings in Sedman have been reused in at last one master's thesis submitted to the University of Liverpool (2010) and one PhD thesis submitted to the University College London (2017). ${ }^{27}$ As these authors only relied on the drawing published in 2002, they could not provide new information about the represented details (headdress/sidelocks, paint, finger position, jewelry) of this figurine, but doubts about the represented pregnancy ("just ...

\footnotetext{
${ }^{26}$ Drawing from the excavation report, photographed by C.-M. Bennett's team. This original photo was used in Sedman 2002: 372 pl. 10.45 .

${ }^{27}$ Trow 2010: 35 fig. 16:\#58; Briffa 2017: 311 fig. 10.1:4, both unpublished.
} 
slightly plumper bellies", Trow 2010: 35) show very well the problems that arise when comparing drawings without having access to the original.

$<199>$ Since very few researchers have the time and funding to look for the original figurines, from Bușayra or elsewhere, in collections all over the world, an open-access database with interactive RTI images which can be enlarged and lightened by each individual scholar from all the sides they need to verify, is an invaluable tool to foster research on these small objects of ancient art and cultural expression.

The RTI taken in 2012 of the figurine Reg. 637 (Figs 6 a-c) can finally provide details that have never been discerned from the drawings: 1. the hair (fringe, sidelocks) coming out from under the headgear on the front is covered at the sides and back by a shoulder-length veil or hood (Figs $7 \mathrm{a}-\mathrm{b}) ; 2$. the figurine exhibits a neckband or choker; 3 . it has almond-shaped, slanting eyes; 4. the hands are "cupping" the breasts; parallel lines mark bracelets on the $<\mathbf{2 0 0}>$ right wrist (Fig. 8); 5. there may be traces of paint on the back (head, shoulders) and above the eyes.

The interpretation of the observed details cannot be developed in the present article ${ }^{28}$ but the richness of details revealed by RTI photography is obvious. Nevertheless, documenting one isolated figurine can only be a first step in building up web-based collections or databases which can be searched, interactively annotated and discussed among specialists.

\section{III.2 Collection building (P. Fornaro)}

The female figurines from Buṣayra are a very good example to show how important it is to build collections so as to be able to compare and corelate the images. A collection in the

\footnotetext{
${ }^{28}$ But see Hunziker-Rodewald 2018; 2019a; 2019 b.
} 
digital domain is a set of equally captured and represented image files comparable by means of perspective, illumination, color, magnification and background. If those attributes are provided, digital image files can be compared to some extent as if the original artifacts were available on the same site. A nice example of this approach is the Fragmentarium project ${ }^{29}$. The Fragmentarium's primary objective is to develop a digital library specialized in medieval manuscript fragment research. Fragments can be virtually combined and analyzed in a webbased environment. In this way, it is possible to digitally recreate medieval handwritings by combining different fragments physically located on various sites.

The same approach can be followed with various types of artifacts, especially with figurines or fragments of figurines. The basic idea behind this is defined in the International Image Interoperability Framework (IIIF, Rosenthaler et al. 2017), ${ }^{30}$ a standard initiated at Stanford University that allows for standardized access to image resources and their metadata via the Internet.

\section{III.3 Outlook: collaborative work}

Single objects and collections can be viewed and analyzed by individual researchers or collaboratively. Collaboration in the digital domain needs an appropriate infrastructure, $<\mathbf{2 0 2}>$ typically, a database that offers simultaneous multiuser access. If such an infrastructure has built-in tools for the analysis of digital objects and their attributes, it is called a virtual research environment (VRE). A VRE typically offers tools for annotating and adding comments to digital objects. It also might allow selecting regions or marking specific spots on a virtual representation. If RTI images are embedded in such a VRE, this would open up for collaborative work. Artifacts can be discussed in detail, as it would not be possible with the physical artifacts. Additionally, such a solution can be used as a sustainable publication

\footnotetext{
${ }^{29} \mathrm{https}$ ://fragmentarium.ms/ (accessed November 21, 2018).

${ }^{30}$ https://iiif.io/ (accessed November 21, 2018).
} 
platform that allows for digital citation. The Digital Humanities Lab of the University of Basel and the University of Strasbourg are planning, in close cooperation with the Swiss National Data and Service Center for the Humanities (DaSCH) ${ }^{31}$, to merge RTI visualization and VRE in a new project called FIGURINE21 by 2019.

\section{<203> Bibliography:}

Amr, A.-J. 1980. A Study of the Clay Figurines and Zoomorphic Vessels of Trans-Jordan during the Iron Age. With Special Reference to their Symbolism and Function. PhD diss., University of London.

Barag, D. 1985. Catalogue of Western Asiatic Glass in the British Museum. Vol. 1. London: British Museum Publications.

Bartlett, J. R. 1989. Edom and the Edomites. Journal for the Study of the Old Testament, Supplement Series 77. Sheffield, UK: Sheffield Academic.

Beck, P. 1995. Human Figurine with Tambourine. In Tel 'Ira: A Stronghold in the Biblical Negev, ed. I. Beit-Arieh, 386-394. Monograph Series 15. Tel Aviv University, Sonia and Marco Nadler Institute of Archaeology: Emery and Claire Yass Publications in Archaeology.

Bennett, C.-M. 1973. Excavations at Buseirah, Southern Jordan, 1971: A Preliminary Report. Levant 5/1:1-11.

Bennett, C.-M. 1974. Excavations at Buseirah, Southern Jordan, 1972: Preliminary Report. Levant 6/1:1-24.

<204> Bienkowski, P. (ed.). 2002. Busayra. Excavations by Crystal-M. Bennett 1971-1980. British Academy Monographs in Archaeology 13, Oxford: Oxford University Press.

\footnotetext{
${ }^{31}$ Rosenthaler et al. 2015.
} 
Bienkowski, P. 1990. Ummm el-Biyara, Tawilan and Buseirah in Retrospect. Levant 22:91109.

Bienkowski, P., L. Sedman. 2001. Busayra and Judah: Stylistic Parallels in the Material Culture. In Studies in the Archaeology of the Iron Age in Israel and Jordan, ed. A. Mazar, 310-325. JSOT Supplement Series 331.

Briffa, J.M. 2017. The Figural World of the Southern Levant During the Late Iron Age. PhD diss., Institute of Archaeology, University College London.

Brown, S.H., B.W. Porter, K. Simon, Ch. Markussen, A.T. Wilson. 2016. Newly documented domestic architecture at Iron Age Busayra (Jordan): preliminary results from a geophysical survey. Antiquity, first published in Issue 350, Volume 90, April 2016, https://www.antiquity.ac.uk/projgall/brown350

Finkelstein I., L. Singer-Avitz. 2009. The Pottery of Khirbet en-Nahas: A Rejoinder, Palestine Exploration Quarterly 141/3:207-218.

Fornaro, P., A. Bianco, A. Kaiser, L. Rosenthaler, L. Schmitt, H. Feldmann. 2017. Enhanced Reflectance Transformation Imaging for Arts and Digital Humanities. 2017 Conference Proceedings, Montreal, Canada, August 2017.

Holland, Th.A. 1975. A Typological and Archaeological Study of Human and Animal Representations in the Plastic Art of Palestine during the Iron Age. 2 vols. $\mathrm{PhD}$ diss., University of Oxford.

Hunziker-Rodewald, R. 2017. Tonfigurinen als Marker von Kulturkontakt: ein Fallbeispiel. Welt des Orients. Traders and the Exchange of Religious Ideas: Case Studies of Material Evidence 47/1:66-105.

Hunziker-Rodewald, R. 2018. Entre pleurs et éclats de rire : Images de femmes dans la culture du Levant Sud. Bulletin de la Société des amis et anciens étudiants de la Faculté de Théologie protestante de Strasbourg 2018:4-8. 
Hunziker-Rodewald, R. 2019a (forthcoming). Molds and Mold-links. A View on the Female Terracotta Figurines from Iron Age II Transjordan. In Iron Age Terracotta Figurines in the Southern Levant, ed. E. D. Darby and I. J. de Hulster. 30 p. Culture and History of the Ancient Near East. Leiden: Brill.

Hunziker-Rodewald, R. 2019b (forthcoming). Conception, grossesse et accouchement. L'enchantement des figurines du Levant Sud à l'âge du fer. In « Figurines féminines nues » (Néolithique-IVe s. apr. J.-C.). Proche-Orient, Égypte, Nubie, Méditerranée orientale, Asie centrale. Actes du colloque international, Strasbourg 25-26 juin 2015, ed. S. Donnat, R. Hunziker-Rodewald and I. Weygand, 241-255. Collection Études d'archéologie et d'histoire ancienne. Paris : Éditions de Boccard.

Kafafi, Z.A. 2014. New Insights on the Copper Mines of Wadi Faynan/Jordan. Palestine Exploration Quarterly 146/4:263-280.

Kletter, R. 1996. The Judean Pillar-Figurines and the Archaeology of Asherah. British Archaeological Reports, International Series 636, Oxford: Tempus reparatum.

Kletter, R. 2014. Iron Age Figurines. In Tel Malhata: A Central City in the Biblical Negev, ed. I. Beit-Arieh and L. Freud. 545-573. Winona Lake IN: Eisenbrauns.

Levy, T., T. Higham, Ch. Bronk Ramsey, N.G. Smith, E. Ben-Yosef, M. Robinson, S. Münger, K, Knabb, J.P. Schulze, M. Najjar, L. Tauxe. 2008. High-precision radiocarbon dating and historical biblical archaeology in southern Jordan. Proceedings of the National Academy of Sciences of the United States of America 105/43:1646016465.

Reich, R. 2011. Reconsidering the Buildings in Area A at Edomite Buseirah. In The Fire Signals of Lachish: Studies in the Archaeology and History of Israel in the Late Bronze Age, Iron Age, and Persian Period in Honor of David Ussishkin, ed. I. Finkelstein and N. Na'aman, 301-306. Grand Rapids IN: Eisenbrauns. 
Rosenthaler, L., P. Fornaro, A. Bianco. 2017. Simple Image Presentation Framework (SIPI) IIIF-based Image-Server IS \&T Archiving Conference Proceedings, Riga.

Rosenthaler, L., P. Fornaro, C. Clivaz. 2015. DASCH: Data and Service Center for the Humanities, http://dx.doi.org/10.1093/llc/fqv051i43-i49, first published online: 8 October 2015.

Sedman, L. 2002. Terracotta figurines. In Busayra. Excavations by Crystal-M. Bennett 19711980, ed. P. Bienkowski, 366-392. British Academy Monographs in Archaeology 13. Oxford: Oxford University Press.

Singer-Avitz, L. 1999. Beersheba - A Gateway Community in Southern Arabian LongDistance Trade in the Eight Century B.C.E. Tel Aviv 26:3-74.

Singer-Avitz, L. 2004. 'Busayra Painted Ware' at Tel Beersheba. Tel Aviv 31:80-89.

Spaer, M. 1991. Ancient Glass in the Israel Museum. Beads and Other Small Objects. Jerusalem, The Israel Museum.

Talbot, W.H.F. 1844. The Pencil of Nature. London: Longman, Brown, Green \& Longmans.

Trow, R.L. 2010. Female Figurines from the Iron Age Transjordan. Dissertation submitted for the Masters degree in Archaeology, University of Manchester 2010.

Tufnell, O. 1958. Lachish IV: The Bronze Age. 2 vols. Wellcome-Marston Archaeological Research Expedition to the Near East. Oxford: Oxford University Press.

Weippert, M. 1982. Edom und Israel. In Theologische Realenzyklopädie. Vol. 9, ed. G. Krause and G. Müller, 291-299. Berlin: Walter de Gruyter. 